\title{
Kesesuaian Kompetensi Mata Kuliah Pendukung TAP ASIP4500 Dengan Kompetensi Lulusan Program D-IV Pengelolaan Arsip dan Rekaman Informasi Universitas Terbuka
}

\section{Dewi Maharani Rachmaningsih}

Universitas Terbuka

\section{ABSTRACT}

TAP (Final Assignment Program) is an exam/evaluation that students must take in the final semester. TAP contains questions about case studies. D-IV Pengelolaan Arsip dan Rekaman Informasi Universitas Terbuka is the only archival program that regulates the final project in the form of a written examination (TAP ASIP4500). The problem is how the TAP ASIP4500 supporting competency of D-IV Pengelolaan Arsip dan Rekaman Informasi. The purpose of the study is to describe the competency TAP ASIP4500 and analyze the suitability of a graduate competency profile. The method used is comparative-descriptive qualitative. Collecting data uses interviews and document study. Study of documents looking for TAP ASIP4500 implementation policies. The results showed that the learning learning outcomes of each supportive course had the characteristics of knowledge and skills competencies, competency characteristics are shown in the table for each subject. The competencies of TAP ASIP4500 are not yet complete to describe their competencies, look mismatch between the competencies TAP ASIP4500 with graduate competency profile
Submitted: $2 / 12 / 2020$

Received: 28/12/2020

*Correspondence:

Dewi Maharani R.

dewi.rachmaningsih@ecampus

ut.ac.id

KEYWORDS:

competency

TAP ASIP4500

graduate profile

Archives and Records

Management

KATA KUNCI:

kompetensi

TAP ASIP4500

lulusan

Pengelolaan Arsip

dan Rekaman

Informasi pendukung TAP ASIP4500 dan bagaimana kesesuaian kompetensi matakuliah pendukung TAP ASIP4500 dalam mencapai tuntutan kompetensi lulusan Program Studi D-IV Pengelolaan Arsip dan Rekaman Informasi. Penelitian ini bertujuan untuk mendeskripsikan capaian pembelajaran matakuliah pendukung TAP ASIP4500 serta menganalisis kesesuaian kompetensi matakuliah pendukung TAP ASIP4500 dalam mencapai tuntutan kompetensi lulusan prodi. Metode yang digunakan dalam menjawab rumusan masalah tersebut adalah kualitatif, khususnya komparatif-deskriptif. Teknik pengumpulan data menggunakan wawancara dan studi dokumen. Studi dokumen digunakan terhadap data - data yang berhubungan dengan kebijakan pelaksaan TAP ASIP4500. Hasil penelitian menunjukkan bahwa capaian pembelajaran matakuliah pendukung TAP ASIP memiliki karakteristik kompetensi pengetahuan dan keterampilan, karaktekristik kompetensi ditampilkan dalam tabel masingmasing matakuliah. Kompetensi matakuliah pendukung TAP ASIP4500 belum sepenuhnya merepresentasikan kompetensi lulusan dan terdapat ketidaksesuaian antara kompetensi matakuliah pendukung TAP ASIP4500 profil kompetensi lulusan. 


\section{PENDAHULUAN}

Perguruan Tinggi merupakan salah satu lembaga pendidikan tinggi di Indonesia yang diharapkan mampu menghasilkan lulusan dengan kompetensi dibidangnya agar siap menghadapi tantangan di dunia kerja. Terdapat beberapa program yang ditawarkan perguruan tinggi, salah satunya adalah diploma. Menurut SK Mendikbud RI/No.056/ V/1994 Program Diploma diarahkan pada hasil lulusan yang menguasai kemampuan dalam melaksanakan pekerjaan yang kompleks (Kemendikbud, 1994). Dengan kata lain program diploma lebih mengutamakan pendidikan melalui penguasaan keahlian dan keterampilan di bidang keilmuannya.

Salah satu contohnya adalah program studi kearsipan di Indonesia. Program studi kearsipan tidak ada yang berjenjang S1, semua program studi kearsipan berdiri dengan jenjang diploma. Berikut adalah daftar perguruan tinggi penyelenggara program studi kearsipan:

Tabel 1. Daftar Prodi Kearsipan di Indonesia

\begin{tabular}{|c|l|l|c|c|}
\hline No & Universitas & \multicolumn{1}{|c|}{ Program Studi } & Jenjang & Predikat \\
\hline 1 & $\begin{array}{l}\text { IAIN Imam Bonjol Pa- } \\
\text { dang }\end{array}$ & $\begin{array}{l}\text { Ilmu Perpus-takaan (d/h. Per- } \\
\text { pustakaan, Arsip dan Dokumen- } \\
\text { tasi) }\end{array}$ & D3 & B \\
\hline 2 & Universitas Diponegoro & Kearsipan & D3 & B \\
\hline 3 & Universitas Gadjah Mada & Kearsipan & D3 & A \\
\hline 4 & Universitas Gadjah Mada & Manajemen Rekod dan Arsip & D4 & $\begin{array}{c}\text { Buka } \\
2019\end{array}$ \\
\hline 5 & Universitas Indonesia & Manajemen Rekod dan Arsip & D3 & A \\
\hline 6 & Universitas Indonesia & Manajemen Rekod dan Arsip & D4 & Buka \\
\hline 7 & Universitas Padjadjaran & Kearsipan & D3 & B \\
\hline 8 & Universitas Padjajaran & Kearsipan Digital & D4 & Buka \\
\hline 9 & Universitas Tanjungpura & Kearsipan & D3 & B \\
\hline 10 & Universitas Terbuka & Kearsipan & D4 & A \\
\hline
\end{tabular}

Sumber: dirangkum dari pddikti kemdikbud

Sebagian besar pendidikan diploma di Indonesia menugaskan mahasiswa untuk membuat Laporan Tugas Akhir sebagai sarana dalam memberikan penilaian atas penguasaan keahlian dan keterampilan mahasiswa. Berbeda dengan hal tersebut, Universitas Terbuka memiliki kebijakan tersendiri dalam memberikan penilaian atas penguasaan pengetahuan dan keterampilan mahasiswa melalui ujian Tugas Akhir Program (TAP). TAP yang diselenggarakan dalam rangka pendidikan jarak jauh mempunyai posisi yang setara dengan tugas pembuatan skripsi atau laporan tugas akhir bagi mahasiswa yang belajar di perguruan tinggi tatap muka (Indrawati, 2007).

Kesetaraan skripsi dan laporan tugas akhir dengan ujian TAP telah diakui, mengingat Perguruan Tinggi Jarak Jauh (PTJJ) memiliki perbedaan dengan Perguruan Tinggi Tatap Muka. Institusi PTJJ memiliki jumlah mahasiswa yang banyak dan heterogen tersebar sehingga tidak menutup kemungkinan beberapa mahasiswa tinggal di tempat terpencil, hal tersebut menyebabkan ketidak efektifan pelaksanaan pembimbingan skripsi maupun tugas akhir. Dengan demikian, UT menerapkan ujian komprehensif berupa TAP sebagai syarat penyelesaian studi yang dapat menghasilkan lulusan yang berkualitas (Universitas Terbuka, 2005). Sebagai bagian dari PTJJ Universitas Terbuka, maka Program Diploma IV Pengelolaan Arsip dan Rekaman 
Informasi ikut melaksanakan penilaian kompetensi mahasiswa melalui Ujian TAP ASIP4500.

Berdasarkan Kepmendiknas RI Nomor 232/U/2000 Tahun 2000, Program Diploma IV dimaksudkan untuk mendidik lulusannya siap kerja terdiri dari $50 \%$ muatan kurikulum adalah mata kuliah praktik dan 50 \% teori (Menteri Pendidikan Nasional, 2000). Sementara itu, dalam Peraturan Presiden (Perpres) Republik Indonesia No 8 Tahun 2012 tentang Kerangka Kualifikasi Nasional Indonesia (KKNI) sebagai kerangka penjenjangan kualifikasi kompetensi yang dapat menyandingkan, menyetarakan, dan mengintegrasikan antara bidang pendidikan dan bidang pelatihan kerja serta pengalaman kerja dalam rangka pemberian pengakuan kompetensi kerja sesuai dengan struktur pekerjaan di berbagai sektor (Presiden RI, 2012). Deskripsi kualifikasi pada KKNI merefleksikan capaian pembelajaran (learning outcomes) yang diperoleh seseorang melalui jalur pendidikan, pelatihan, pengalaman kerja, dan pembelajaran mandiri. Capaian pembelajaran merupakan internalisasi dan akumulasi yang dicapai melalui proses pendidikan yang terstruktur dan mencakup suatu bidang ilmu/keahlian tertentu.

D-IV Pengelolaan Arsip dan Rekaman Informasi UT menyelenggarakan Ujian TAP ASIP4500 sebagai sarana untuk mengukur penguasaan kompetensi lulusan. Tugas yang dihadapi oleh mahasiswa berupa serangkaian tugas yang berbentuk permasalahan, kasus-kasus, atau pertanyaan yang diangkat dari masalah nyata pembelajaran bidang studi yang harus dipecahkan secara komprehensif dengan menggunakan konsep dan teori yang telah dipelajari pada mata kuliah yang terkait (FAQIH, 2014). Ujian TAP ASIP4500 menuntut mahasiswa untuk mengaplikasikan pengetahuan, sikap, dan keterampilan yang diperolehnya selama proses perkuliahan. Pengaplikasian kompetensi tersebut terlihat dalam tanggapan/jawaban mahasiswa ketika memecahkan contoh kasus/masalah di bidang pengelolaan arsip dan rekaman informasi secara komprehensif. Tujuannya adalah agar mahasiswa dapat menunjukkan keahlian dan keterampilannya dalam memecahkan permasalahan pengelolaan arsip dan rekaman informasi. Namun demikian, apakah TAP ASIP 4500 telah sesuai dengan kompetensi lulusan Program Diploma IV Pengelolaan Arsip dan Rekaman Informasi? Guna mengetahui kesesuaian tersebut maka diperlukan kajian terkait kompetensi mata kuliah pendukung TAP ASIP4500. Batasan ruang lingkup dalam penelitian ini hanya pada capaian pembelajaran matakuliah pendukungnya, antara lain ASIP4402 Penilaian dan Penyusutan Arsip, ASIP4432 Otomasi Dalam Kearsipan, ASIP4436 Perancangan Skema Klasifikasi dan Tesaurus, ASIP4434 Perancangan Jadwal Retensi Arsip.

\section{TINJAUAN PUSTAKA}

Penelitiaan sejenis telah dilakukan oleh Endang Indrawati dan Faqih. Penelitian Endang berjudul Penjaminan Kualitas Lulusan Melalui Penyelenggaraan Tugas Akhir Program, melalui penelitian tersebut dapat disimpulkan bahwa penjaminan kualitas lulusan pada Program Studi S1 PKP UT dilakukan dengan jalan memodifikasi dan melakukan kontrol penjaminan mekanisme penyelenggaraan TAP. Modifikasi yang dimaksud adalah mengkombinasikan tutorial tatap muka, pembimbingan pembuatan karya ilmiah, dan ujian akhir TAP serta melakukan kontrol nilai dan monev di UPBJJ. Mekanisme tersebut diharapkan dapat memperbaiki penyelenggaraan TAP UT. Penelitian selanjutnya berjudul Revitalisasi Mata Kuliah TAP Program S1 PGSD Untuk Mendukung Penyiapan Kompetensi Profesional Calon Lulusan yang dilakukan oleh Faqih, hasil penelitian berguna untuk revitalisasi matakuliah TAP dengan mereaktualisasi perangkat tutorial serta mengacu pada kurikulum. Upaya revitalisasi guna menyiapkan calon lulusan yang mempunyai kompetensi guru kelas profesional. Penelitian dalam artikel ini berbeda dari penelitian sebelumnya dan belum pernah 
dilakukan karena objek penelitiannya adalah kompetensi TAP ASIP4500 dan kompetensi Program Studi Pengelolaan Arsip dan Rekaman Informasi. Tujuan penelitian adalah untuk mendeskripsikan capaian pembelajaran matakuliah pendukung TAP ASIP4500 serta menganalisis kesesuaian kompetensi matakuliah pendukung TAP ASIP4500 dengan kompetensi lulusan Program Diploma IV Pengelolaan Arsip dan Rekaman Informasi.

Kompetensi atau dalam Bahasa Inggris disebut dengan competence memiliki pengertian sebagai kemampuan atau kapabilitas. Kata "mampu" dapat dipahami berbeda sesuai dengan konteks penggunaannya. Terdapat 3 jenis kompetensi yang berkembang (Hutapea, 2008), yaitu:

1. Kompetensi teknis atau fungsional, untuk menggambarkan tanggungjawab, tantangan dan sasaran kerja yang harus dilakukan.

2. Kompetensi perilaku menekankan pada perilaku produktif yang harus dimiliki serta diperagakan oleh seseorang dalam melaksanakan pekerjaan.

3. Kompetensi pengetahuan dan keterampilan individu menekankan pada kepemilikan atau penguasaan pengetahuan dan keterampilan.

Dengan demikian, dapat disimpulkan bahwa kompetensi merupakan kemampuan yang dimiliki oleh seseorang untuk selanjutnya ditunjukkan dan diapikasikan keterampilannya dalam suatu pekerjaan. Selanjutnya Hutapea menjelaskan pembentukan kompetensi dipengaruhi oleh dua faktor, yaitu:

1. faktor internal, merupakan faktor bawaan yang bersifat genetik

2. faktor eksternal, akumulatif pendidikan dan pengalaman yang mempengaruhi perkembangan kompetensi

Guna mempermudah dalam menilai, mengukur, mengevaluasi dan membuktikan implementasi kompetensi maka diperlukan suatu standar. Standar kompetensi merupakan daftar kompetensi setiap pekerjaan (jabatan) yang disajikan secara umum untuk dapat dijadikan sebagai ukuran pelaksanaan kompetensi (Hutapea, 2008). Pada umumnya standar kompetensi dikeluarkan oleh lembaga resmi pelatihan maupun lembaga pemerintahan. Sebagai contoh kompetensi arsiparis di Indonesia tertuang dalam Peraturan Kepala Arsip Nasional Republik Indonesia Nomor 23 Tahun 2017 tentang Standar Kualitas Kerja Arsiparis (ANRI, 2017). Dalam hal penelitian ini standar kompetensi yang digunakan mengacu pada Kerangka Kualifikasi Nasional Indonesia (KKNI).

Peraturan Presiden Nomor 8 Tahun 2012 tentang Kerangka Kualifikasi Nasional Indonesia (KKNI) dan Undang-Undang Nomor 12 Tahun 2012 tentang Pendidikan Tinggi, mendorong semua perguruan tinggi untuk menyesuaikan diri dengan ketentuan tersebut. Amanat Undang-Undang Nomor 12 Tahun 2012 Pasal 35 ayat 2 tentang kurikulum menyebutkan bahwa Kurikulum Pendidikan Tinggi dikembangkan oleh setiap Perguruan Tinggi dengan mengacu pada Standar Nasional Pendidikan Tinggi untuk setiap Program Studi yang mencakup pengembangan kecerdasan intelektual, akhlak mulia, dan keterampilan.

Standar Nasional Pendidikan Tinggi telah tertuang dalam Permenristekdikti No 44 tahun 2015. Standar kompetensi lulusan merupakan kriteria minimal tentang kualifikasi kemampuan lulusan yang mencakup sikap, pengetahuan dan keterampilan yang dinyatakan dalam rumusan capaian pembelajaran lulusan (Permenristekdikti, 2015). Rumusan capaian pembelajaran lulusan tidak terlepas dari standar isi pembelajaran. Standar isi pebelajaran merupakan kriteria minimal tingkat kedalaman dan keluasan materi pembelajaran, sebagaimana dinyatakan pada tabel berikut. 
Tabel 2. Tingkat Kedalaman dan Keluasan Materi Pembelajaran

\begin{tabular}{|l|l|l|}
\hline No & \multicolumn{1}{|c|}{ Lulusan } & \multicolumn{1}{c|}{ Tingkat kedalaman dan keluasan materi } \\
\hline 1 & D-I & $\begin{array}{l}\text { menguasai konsep umum, pengetahuan, dan keterampilan } \\
\text { operasional lengkap }\end{array}$ \\
\hline 2 & D-II & $\begin{array}{l}\text { menguasai prinsip dasar pengetahuan dan keterampilan pada bidang } \\
\text { keahlian tertentu }\end{array}$ \\
\hline 3 & D-III & $\begin{array}{l}\text { menguasai konsep teoritis bidang pengetahuan dan keterampilan } \\
\text { tertentu secara umum }\end{array}$ \\
\hline 4 & D-IV/S-1 & $\begin{array}{l}\text { menguasai konsep teoritis bidang pengetahuan dan keterampilan } \\
\text { tertentu secara umum dan konsep teoritis bagian khusus dalam }\end{array}$ \\
\hline 5 & S-2 / Sp-1 & $\begin{array}{l}\text { menguasai teori aplikasi bidang pengetahuan dan keterampilan } \\
\text { tertentu }\end{array}$ \\
\hline 6 & Profesi & $\begin{array}{l}\text { menguasai teori aplikasi bidang pengetahuan dan keterampilan } \\
\text { tertentu }\end{array}$ \\
\hline 7 & S-3 / Sp-2 & $\begin{array}{l}\text { Menguasai filosofi keilmuan bidang pengetahuan dan keterampilan } \\
\text { tertentu }\end{array}$ \\
\hline
\end{tabular}

Tingkat kedalaman dan keluasan materi pembelajaran tercantum dalam SN-DIKTI pasal 9 ayat 2 bersifat kumulatif dan atau integratif, dituangkan dalam bahan kajian yang distrukturkan dalam bentuk mata kuliah. Tingkat penguasaan pengetahuan yang diperlukan untuk membangun kemampuan kerja (keterampilan khusus) program sarjana terapan/ D-IV menurut Peraturan Presiden Nomor 8 Tahun 2012 adalah menguasai konsep teoritis bidang pengetahuan dan keterampilan tertentu secara umum dan konsep teoritis bagian khusus dalam bidang pengetahuan dan keterampilan tersebut secara mendalam. Sedangkan kata kunci tingkat kemampuan kerja (keterampilan khusus) untuk program sarjana terapan/ D-IV adalah mengaplikasikan, mengkaji, membuat desain, memanfaatkan IPTEKS, menyelesaikan masalah.

Tingkat penguasaan kompetensi akan berpengaruh pada kinerja, seperti yang terlihat pada hasil penelitian yang dilakukan oleh Bukhori (2019). Kesimpulan atas penelitian tersebut adalah keseluruhan kompetensi arsiparis terdiri dari pengetahuan, keterampilan dan sikap mempengaruhi kinerja arsiparis di ANRI.

Selanjutnya penekanan akan kompetensi arsiparis tersirat dalam PP Nomor 28 Tahun 2012, pasal 151 ayat (2) tentang fungsi dan tugas arsiparis antara lain:

a. menjaga terciptanya arsip dari kegiatan yang dilakukan oleh lembaga negara, pemerintahan daerah, lembaga pendidikan, perusahaan, organisasi politik, dan organisasi kemasyarakatan;

b. menjaga ketersediaan arsip yang autentik dan terpercaya sebagai alat bukti yang sah;

c. menjaga terwujudnya pengelolaan arsip yang andal dan pemanfaatan arsip sesuai dengan ketentuan peraturan perundang-undangan;

d. menjaga keamanan dan keselamatan arsip yang berfungsi untuk menjamin arsiparsip yang berkaitan dengan hak-hak keperdataan rakyat melalui pengelolaan dan pemanfaatan arsip yang autentik dan terpercaya;

e. menjaga keselamatan dan kelestarian arsip sebagai bukti pertanggungjawaban dalam kehidupan bermasyarakat, berbangsa, dan bernegara;

f. menjaga keselamatan aset nasional dalam bidang ekonomi, sosial, politik, budaya, pertahanan, serta keamanan sebagai identitas dan jati diri bangsa; dan

g. menyediakan informasi guna meningkatkan kualitas pelayanan publik dalam pengelolaan dan pemanfaatan arsip yang autentik dan terpercaya. 
Arsiparis merupakan profesi, guna meningkatkan eksistensi dan optimalisasi maka selayaknya profesi lainnya memiliki asosiasi. Asosiasi yang dikenal dengan istilah AAI (Asosiasi Arsiparis Indonesia). AAI telah menyusun kode etik profesi sebagai standar moralitas bagi Arsiparis Indonesia dalam menjalankan tugas, kewenangan dan tanggungjawab profesi kearsipan (Sudiyanto, 2013). Kode etik arsiparis tercantum dalam Keputusan Pengurus Nasional Asosiasi Arsiparis Indonesia Nomor 06/ AAI/2009, keputusan tersebut merupakan pola aturan/pedoman etika bagi arsiparis dalam rangka melaksanakan kegiatan bidang pekerjaannya. Berdasarkan kode etik tersebut tertuliskan bahwa arsiparis bertanggungjawab atas pengelolaan arsip, mulai dari penciptaan, penggunaan, pemeliharaan, penyusutan, penilaian, akuisisi, deskripsi, pelestarian sampai dengan akses dan pemanfaatan arsip demi kemaslahatan bangsa.

Secara umum, perguruan tinggi perlu mengacu pada Peraturan Presiden Nomor 8 Tahun 2012 tentang Kerangka Kualifikasi Nasional Indonesia (KKNI), Undang-Undang Nomor 12 Tahun 2012 tentang Pendidikan Tinggi, Permenristekdikti No 44 tahun 2015 tentang SNPT. Kemudian secara lebih spesifik, Perguruan Tinggi Penyelenggara Program Studi Kearsipan perlu mengacu pada Peraturan Kepala Arsip Nasional Republik Indonesia Nomor 23 Tahun 2017, PP Nomor 28 Tahun 2012, Keputusan Pengurus Nasional Asosiasi Arsiparis Indonesia Nomor 06/AAI/2009 guna mendesain kompetensi calon arsiparis yang berkompeten di dunia kerja.

\section{METODE PENELITIAN}

Penelitian ini berusaha mendeskripsikan dan menganalisis kesesuaian mata kuliah pendukung TAP ASIP4500 dengan kompetensi lulusan Program Studi D-IV Pengelolaan Arsip dan Rekaman Informasi. Oleh karena itu, peneliti menggunakan pendekatan kualitatif deskriptif-komparatif. Penelitian yang menghasilkan informasi berupa catatan dan data deskriptif yang terdapat di dalam teks yang diteliti (Mantra I, 2008).

Fokus penelitian dibatasi pada kompetensi mata kuliah pendukung dan kompetensi lulusan. Pembatasan fokus penelitian dengan tujuan agar penelitian lebih terarah dan tidak melebar. Selanjutnya data yang diteliti antara lain (1) kompetensi mata kuliah pendukung TAP ASIP4500, (2) kompetensi lulusan Program Studi Diploma IV Pengelolaan Arsip dan Rekaman Informasi. Fokus penelitian bersifat tentatif seiring dengan perkembangan penelitian. Moleong menyatakan bahwa fokus penelitian dimaksudkan untuk membatasi studi kualitatif, sekaligus membatasi penelitian guna memilih data yang relevan dan yang baik (2007:237).

Sumber data yang digunakan dalam penelitian ini antara lain (1). sumber data primer, berupa wawancara dengan informan kunci, seperti Ketua Program Studi D-IV Pengelolaan Arsip dan Rekaman Informasi serta pakar pengelolaan arsip dan rekaman informasi, (2) sumber data sekunder, berupa dokumen, catatan, laporan, serta arsip yang berkaitan dengan penelitian, khususnya mengenai kompetensi matakuliah pendukung TAP ASIP4500 dan kompetensi lulusan.

Penelitian dilakukan pada Program Studi D-IV Pengelolaan Arsip dan Rekaman Informasi. Objek penelitian adalah kompetensi mata kuliah pendukung TAP ASIP4500 dan kompetensi lulusan sedangkan subjek penelitiannya adalah mata kuliah pendukungnya dan turunan dari visi misi program studi terhadap lulusan pada masa studi 2019.2. Analisis data dilakukan dengan cara melakukan reduksi, membandingkan, dan menganalisis data - data berikut: 
Tabel 3. Memetakan Sumber Objek Yang Akan Dianalisis

\begin{tabular}{|c|c|c|}
\hline Objek Penelitian & Sumber & Rincian \\
\hline \multirow{4}{*}{$\begin{array}{l}\text { Kompetensi } \\
\text { Matakuliah Pen- } \\
\text { dukung TAP ASIP } 4500\end{array}$} & $\begin{array}{l}\text { BMP ASIP4402 Penilaian dan } \\
\text { Penyusutan Arsip ( } 3 \text { sks) }\end{array}$ & $\begin{array}{l}\text { Matakuliah ini terdiri dari } \\
9 \text { modul dengan total } 18 \\
\text { KB }\end{array}$ \\
\hline & $\begin{array}{l}\text { BMP ASIP4432 Otomasi Dalam } \\
\text { Kearsipan ( } 3 \text { sks) }\end{array}$ & $\begin{array}{l}\text { Matakuliah ini terdiri dari } \\
9 \text { modul dengan total } 24 \\
\text { KB }\end{array}$ \\
\hline & $\begin{array}{l}\text { BMP ASIP4436 Perancangan } \\
\text { Skema Klasifikasi dan Tesau- } \\
\text { rus } \\
(3 \mathrm{sks})\end{array}$ & $\begin{array}{l}\text { Mata kuliah ini terdiri dari } \\
9 \text { modul dengan total } 27 \\
\text { KB }\end{array}$ \\
\hline & $\begin{array}{l}\text { ASIP4434 Perancangan Jadwal } \\
\text { Retensi Arsip ( } 3 \mathrm{sks} \text { ) }\end{array}$ & $\begin{array}{l}\text { Matakuliah ini terdiri dari } \\
9 \text { modul dengan total } 18 \\
\text { KB }\end{array}$ \\
\hline \multirow{2}{*}{$\begin{array}{l}\text { Kompetensi Lulusan } \\
\text { Program Diploma IV } \\
\text { Pengelolaan Arsip dan } \\
\text { Rekaman Informasi }\end{array}$} & Katalog Periode 2019/2020 & $\begin{array}{l}\text { Terdiri dari } 14 \text { keterampi- } \\
\text { lan }\end{array}$ \\
\hline & Katalog Periode 2019/2020 & $\begin{array}{l}\text { Terdiri dari } 13 \text { penge- } \\
\text { tahuan }\end{array}$ \\
\hline
\end{tabular}

Sumber: arsip milik Prodi Pengelolaan Arsip Rekaman dan Informasi Universitas Terbuka

Selanjutnya setelah data tersebut didapat, kemudian dideskripsikan dan dianalisis agar mudah dalam menarik kesimpulan. Agar hasil penelitian dapat dipertanggungjawabkan, maka diperlukan pengecekan/pengujian keabsahan data apakah data yang disajikan valid atau tidak. Pengujian keabsahan data dilakukan dengan menggunakan trianggulasi teknik. Menurut Sugiyono, triangulasi teknik berarti menggunakan teknik pengumpulan data yang berbeda-beda untuk mendapatkan data dari sumber data yang sama (Sugiyono, 2013). Pengujian keabsahan data dalam penelitian menggunakan wawancara terhadap ketua prodi serta dokumentasi untuk mendapatkan kesesuaian hasil analisis.

\section{HASIL DAN PEMBAHASAN}

Sebagai bagian dalam proses evaluasi, maka TAP ASIP 4500 didesain dengan muatan soal yang objektif. Setelah dilakukan studi dokumen maka ditemukan penjelasan pada Panduan TAP FHISIP tahun 2018 yang menjelaskan karakteristik soal TAP sebagai berikut:

1. Menuntut kemampuan berfikir hingga tingkat evaluasi. Soal ujian TAP tidak hanya mengukur pengetahuan atau pemahaman mahasiswa, namun mahasiswa diminta mengevaluasi suatu fenomena,

2. Subtansi TAP bersifat komprehensif, dalam artian jawaban yang diminta harus mengaitkan unsur keilmuan dari berbagai matakuliah dengan fenomena nyata,

3. TAP merupakan ujian akhir program sarjana atau sarjana terapan yang mengukur penguasaan kompetensi mahasiswa atas suatu program studi yang diambilnya.

Guna menunjang evaluasi kompetensi maka pihak Program Diploma IV Pengelolaan Arsip dan Rekaman Informasi menunjuk beberapa matakuliah pendukung TAP ASIP 4500. Dalam kurikulum Program Studi D-IV Pengelolaan Arsip dan Rekaman Informasi dijelaskan bahwa matakuliah pendukung TAP ASIP4500 terdiri atas 4 (empat) matakuliah, yaitu: 
1. ASIP4402 Penilaian dan Penyusutan Arsip, mata kuliah ini membahas penilaian rekod, jangka waktu dan pemusnahan.

2. ASIP4432 Otomasi Dalam Kearsipan, merupakan mata kuliah keahlian dan keterampilan teknologi di bidang kearsipan khususnya implementasi otomasi.

3. ASIP4436 Perancangan Skema Klasifikasi dan Tesaurus, merupakan materi substantif ilmu kearsipan yang harus diimplementasikan dalam pengelolaan arsip.

4. ASIP4434 Perancangan Jadwal Retensi Arsip, menganalisis konsep manajemen arsip dinamis, mampu menyusun dan mengimplementasikan jadwal retensi arsip dalam proses penyusutan arsip.

Ketua Program Diploma IV Pengelolaan Arsip dan Rekaman Informasi menjelaskan bahwa periode tahun akademik 2019.2 memiliki 2 struktur kurikum, yaitu struktur kurikulum 2018/2019.1 lama dan struktur kurikulum 2018/2019.1 baru. Perbedaan mendasar dalam struktur kurikulum tersebut adalah adanya perampingan matakuliah Perancangan Skema Klasifikasi dan Tesaurus. Struktur kurikulum lama terdiri dari lima matakuliah, kemudian struktur kurikulum baru terdiri dari empat matakuliah. Matakuliah tersebut dipilih karena pihak prodi menganggap otomasi, klasifikasi, tesaurus, JRA, penilaian dan penyusutan arsip sebagai matakuliah inti ilmu kearsipan.

Tabel berikut menjelaskan tentang capaian pembelajaran matakuliah pendukung TAP ASIP4500. Masing - masing matakuliah pendukung terdiri dari 3 sks dan memiliki kompetensi umum. Kompetensi umum tersebut di turunkan ke dalam kompetensi khusus yang terdiri dari 9 capaian pembelajaran.

$\mathrm{T}$

Tabel 4. Rincian Capaian Pembelajaran Matakuliah Pendukung TAP ASIP

\begin{tabular}{|c|c|c|c|c|c|c|c|c|c|}
\hline \multirow{4}{*}{$\begin{array}{l}\text { ASIP4402 } \\
\text { Penilaian } \\
\text { dan } \\
\text { Penyusutan } \\
\text { Arsip }\end{array}$} & \multicolumn{9}{|c|}{$\begin{array}{l}\text { Kompetensi umum } \\
\text { Mahasistva memahami pentingnya proses seleksi dan penilaian serta menggunakan jadwal retensi arsip } \\
\text { secara efektif dan efisien sehingga mampu melaksanakan penyusutan arsip } \\
\text { sesuai peraturan perundang undangan yang berlaku. }\end{array}$} \\
\hline & \multicolumn{9}{|c|}{ Kompetensi Khusus } \\
\hline & A & \begin{tabular}{|c|}
$\mathrm{B}$ \\
\end{tabular} & $\mathrm{C}$ & $\mathrm{D}$ & \begin{tabular}{|c|c|}
$\mathrm{E}$ & \\
\end{tabular} & $\mathrm{F}$ & \begin{tabular}{c|l}
$\mathrm{G}$ &
\end{tabular} & \begin{tabular}{|l|l|}
$\mathrm{H}$ & \\
\end{tabular} & $\mathrm{I}$ \\
\hline & \begin{tabular}{|c|}
$\begin{array}{c}\text { konsep } \\
\text { dasar } \\
\text { penyusutan } \\
\text { arsip }\end{array}$ \\
\end{tabular} & \begin{tabular}{|c|} 
aspek \\
hukum \\
penyusutan \\
arsip
\end{tabular} & $\begin{array}{l}\text { penilaian } \\
\text { arsip }\end{array}$ & $\begin{array}{l}\text { praktek } \\
\text { penilaian } \\
\text { arsip }\end{array}$ & jadwal & \begin{tabular}{|c|} 
praktek \\
penyusunan \\
JRA \\
\end{tabular} & \begin{tabular}{|c|} 
prosedur \\
teknik \\
penyusutan \\
arsip \\
\end{tabular} & \begin{tabular}{|c|} 
praktek \\
penyusutan \\
arsip \\
dengan jra \\
\end{tabular} & \begin{tabular}{|c|} 
praktek \\
penyusuta \\
n arsip nor \\
jra \\
\end{tabular} \\
\hline \multirow[b]{3}{*}{$\begin{array}{l}\text { ASIP4432 } \\
\text { Otomasi } \\
\text { Dalam } \\
\text { Kearsipan }\end{array}$} & \multicolumn{9}{|c|}{$\begin{array}{l}\text { Kompetensi Umum } \\
\text { laskan konsep dan me }\end{array}$} \\
\hline & A & \begin{tabular}{|c|}
$\mathrm{B}$ \\
\end{tabular} & \begin{tabular}{l|l}
$\mathrm{C}$ & \\
\end{tabular} & \begin{tabular}{|l|l|l}
$\mathrm{D}$ & \\
\end{tabular} & \begin{tabular}{|l|l|l}
$\mathrm{E}$ & \\
\end{tabular} & \begin{tabular}{|l|l|l|l}
$\mathrm{F}$ & \\
\end{tabular} & \begin{tabular}{|l|l|l}
$\mathrm{G}$ & \\
\end{tabular} & \begin{tabular}{|l|l|}
$\mathrm{H}$ &
\end{tabular} & \begin{tabular}{|l|} 
I \\
\end{tabular} \\
\hline & \begin{tabular}{|c|} 
konsep \\
manajemen, \\
sistem, dan \\
teknologi \\
informasi \\
\end{tabular} & \begin{tabular}{|c|} 
sejarah \\
perkem- \\
bangan \\
manajemen \\
sistem dan \\
TI \\
\end{tabular} & \begin{tabular}{|c|} 
keterkaitan \\
TI dengan \\
pengelolaan \\
arsip
\end{tabular} & $\begin{array}{l}\text { konsep } \\
\text { otomasi } \\
\text { kearsipan }\end{array}$ & $\begin{array}{l}\text { Supra- } \\
\text { stuktur } \\
\text { otomasi } \\
\text { kearsipan }\end{array}$ & $\begin{array}{l}\text { jaringan } \\
\text { komputer } \\
\text { kearsipan }\end{array}$ & $\begin{array}{l}\text { pangkalan } \\
\text { data arsip }\end{array}$ & $\begin{array}{l}\text { aplikasi } \\
\text { pengelolaan } \\
\text { arsip }\end{array}$ & $\begin{array}{l}\text { implement } \\
\text { si otomasi } \\
\text { kearsipan }\end{array}$ \\
\hline \multirow{4}{*}{$\begin{array}{c}\text { ASIP4436 } \\
\text { Perancangan } \\
\text { Skema } \\
\text { Klasifikasi } \\
\text { dan } \\
\text { Tesaurus }\end{array}$} & \multicolumn{9}{|c|}{ Kompetensi umum } \\
\hline & \multicolumn{9}{|c|}{ Kompetensi Khusus } \\
\hline & A & $\mathrm{B}$ & $\mathrm{C}$ & \begin{tabular}{l|l}
$\mathrm{D}$ & \\
\end{tabular} & \begin{tabular}{|c|}
$\mathrm{E}$ \\
\end{tabular} & $\mathrm{F}$ & $\mathrm{G}$ & $\mathrm{H}$ & I \\
\hline & \begin{tabular}{|c|} 
karakteristik \\
arsip dan \\
pengertian \\
klasifikasi \\
arsip
\end{tabular} & $\begin{array}{c}\text { perangkat } \\
\text { klasifikasi } \\
\text { dan tesaurus } \\
\text { fungsi }\end{array}$ & $\begin{array}{c}\text { perancangan } \\
\text { skema } \\
\text { klasifikasi } \\
\text { arsip }\end{array}$ & \begin{tabular}{|c|} 
kebutuhan \\
perancangan \\
tesaurus \\
\end{tabular} & \begin{tabular}{|} 
penggunaan \\
klasifikasi \\
arsip dalam \\
pengelolaan \\
arsip \\
dinamis
\end{tabular} & \begin{tabular}{|c|} 
penggunaan \\
tesaurus \\
dalam temu \\
balik \\
informasi
\end{tabular} & \begin{tabular}{|c|} 
pengelolaan \\
seri arsip \\
berdasarkan \\
skema \\
klasifikasi
\end{tabular} & \begin{tabular}{|c|} 
hubungan \\
antara \\
tesaurus dar \\
jadwal \\
retensi \\
arsip \\
\end{tabular} & $\begin{array}{c}\text { model } \\
\text { pengelolaa } \\
\mathrm{n} \text { arsip }\end{array}$ \\
\hline
\end{tabular}




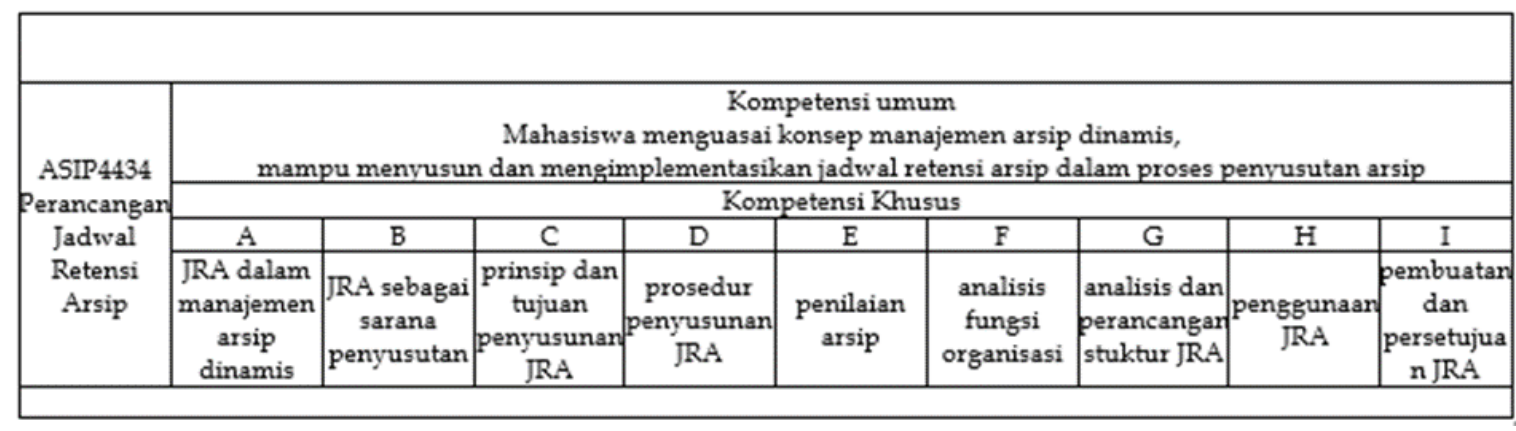

Keempat matakuliah pendukung TAP ASIP4500 tersebut memiliki karakteristik masing masing. Subtansi materi dari setiap karakteristik matakuliah berpengaruh pada capaian kompetensi, contohnya capaian kompetensi MK ASIP4402 diharapkan mahasiswa dapat memahami proses seleksi dan penilaian arsip guna pelaksanaan penyusutan arsip.

Keempat mata kuliah tersebut dipilih sebagai pendukung TAP ASIP4500 karena mata kuliah inti ilmu kearsipan. Kesimpulan atas kesesuaian masing masing kompetensi matakuliah pendukung TAP ASIP4500 dan kompetensi lulusan Program Diploma IV Pengelolaan Arsip dan Rekaman Informasi dapat terlihat pada hasil analisis data berikut:

Tabel 5. Analisis Tingkat Kesesuaian Kompetensi Keterampilan

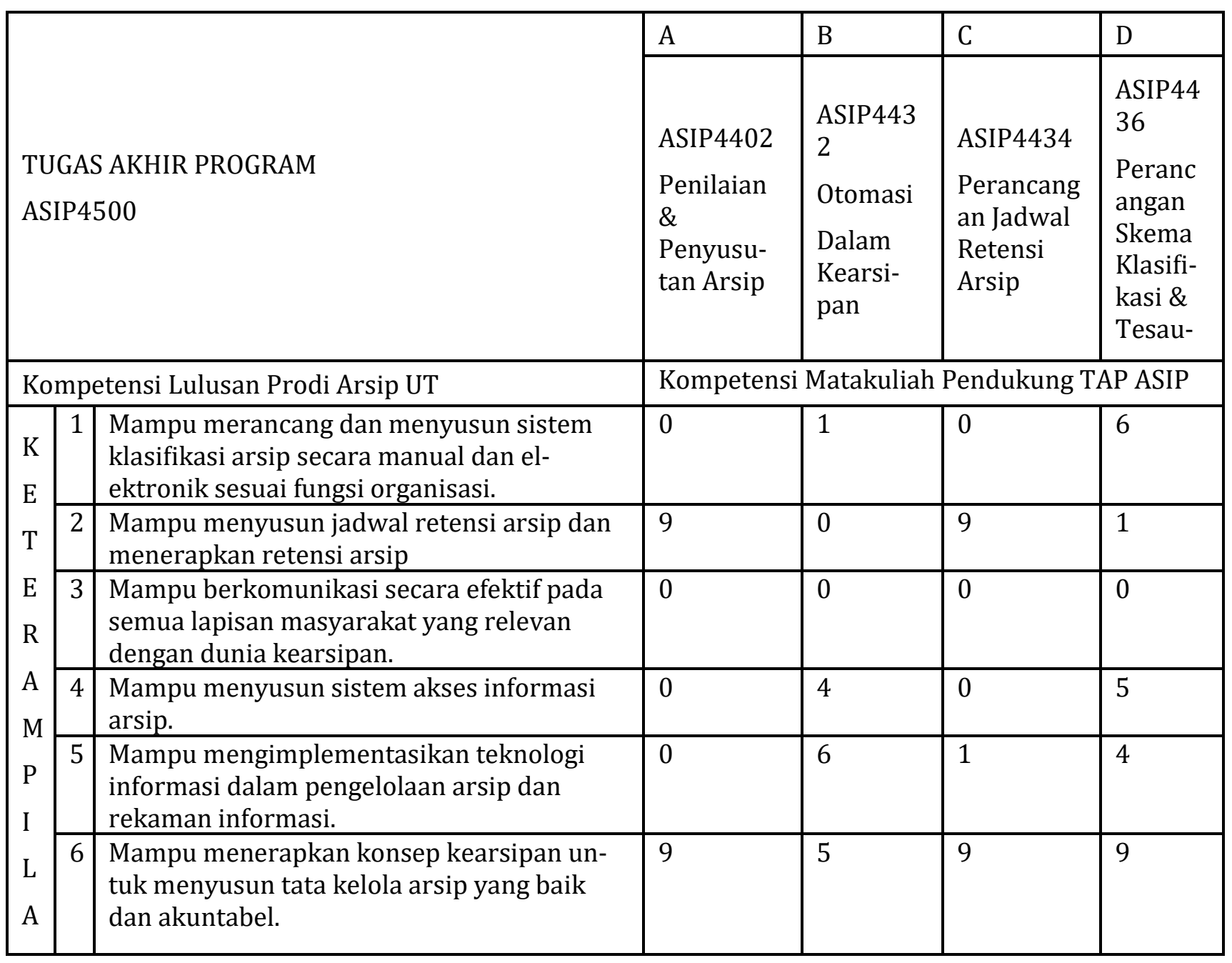




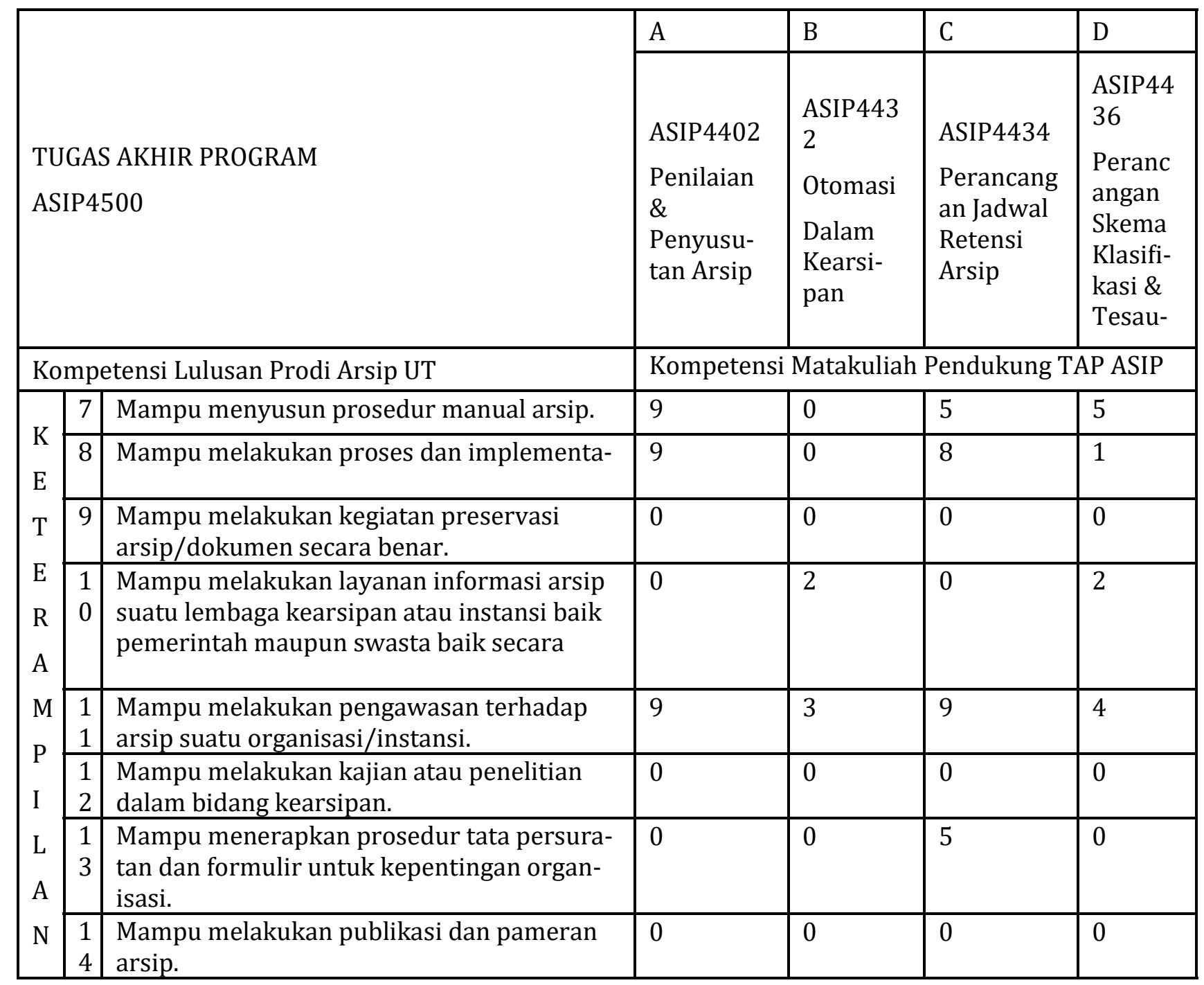

Program Diploma IV Pengelolaan Arsip dan Rekaman Informasi memiliki 14 kompetensi keterampilan lulusan, selanjutnya kompetensi keterampilan tersebut dibandingkan dengan 9 capaian pembelajaran dari masing masing kompetensi matakuliah pendukung. Sejumlah 28\% kompetensi keterampilan tidak terakomodir dalam mata kuliah pendukung TAP ASIP4500. Kompetensi keterampilan yang dimaksud yaitu, kemampuan untuk melakukan komunikasi efektif, preservasi, meneliti, prosedur tata persuratan serta publikasi dan pameran arsip. 
Tabel 6. Analisis Tingkat Kesesuaian Kompetensi Pengetahuan

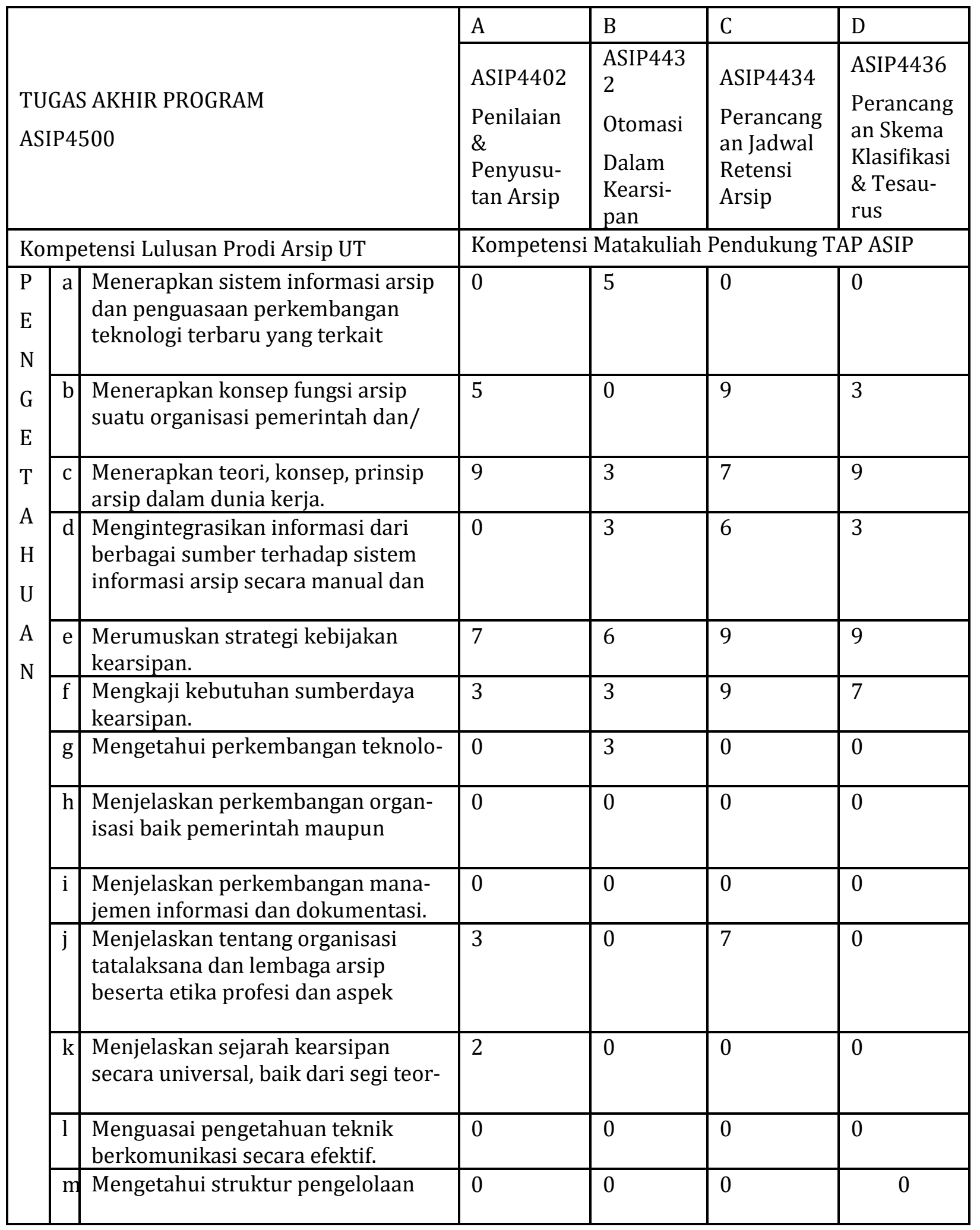

Terdapat 30\% dari total 13 kompetensi pengetahuan lulusan yang belum terakomodir dalam matakuliah pendukung TAP ASIP4500. Setelah dilakukan tabulasi dapat diketahui bahwa matakuliah pendukung TAP ASIP4500 belum sepenuhnya sesuai dengan kompetensi pengetahuan mahasiswa, antara lain tentang perkembangan organisasi, perkembangan manajemen informasi dokumentasi, komunikasi efektif dan pengelolaan administrasi pemerintah. 
Sebanyak 70,4\% kompetensi matakuliah pendukung TAP ASIP4500 telah sesuai dengan kompetensi lulusan Program Diploma IV Pengelolaan Arsip dan Rekaman Informasi. Terdapat 27 kompetensi lulusan (terdiri dari 14 keterampilan dan 13 pengetahuan) serta 36 kompetensi matakuliah pendukung TAP ASIP4500 (terdiri dari 9 capaian pembelajaran di tiap matakuliah). Sepuluh besar prosentase kompetensi yang sesuai antara matakuliah pendukung dan lulusan tersaji dalam tabel berikut:

Tabel 7. Kesesuaian Hasil Analisis Kompetensi

\begin{tabular}{|l|l|l|l|l|}
\hline $\begin{array}{l}\text { N } \\
\underline{\mathbf{O}}\end{array}$ & $\begin{array}{l}\text { Kode } \\
\text { Indi- }\end{array}$ & $\begin{array}{l}\text { Jenis } \\
\text { Kompetensi }\end{array}$ & $\begin{array}{l}\text { Prosen- } \\
\text { tase }\end{array}$ \\
\hline 1 & 6 & Keterampilan & $\begin{array}{l}\text { Menerapkan konsep kearsipan untuk menyusun tata } \\
\text { kelola arsip yang baik \& akuntabel. }\end{array}$ & 88,9 \\
\hline 2 & e & Pengetahuan & Merumuskan strategi kebijakan kearsipan. & 86,1 \\
\hline 3 & c & Pengetahuan & $\begin{array}{l}\text { Menerapkan teori, konsep, prinsip arsip dalam dunia } \\
\text { kerja. }\end{array}$ & 77,8 \\
\hline 4 & 11 & Keterampilan & $\begin{array}{l}\text { Mampu melakukan pengawasan terhadap arsip suatu } \\
\text { organisasi/instansi. }\end{array}$ & 69,4 \\
\hline 5 & f & Pengetahuan & Mengkaji kebutuhan sumberdaya kearsipan. & 61,1 \\
\hline 6 & 7 & Keterampilan & Mampu menyusun prosedur manual arsip. & 52,8 \\
\hline 7 & 2 & Keterampilan & Mampu menyusun jadwal retensi arsip dan menerapkan & 52,8 \\
\hline 8 & 8 & Keterampilan & Mampu melakukan proses dan implementasi akuisisi & 50,0 \\
\hline 9 & b & Pengetahuan & Menerapkan konsep fungsi arsip suatu organisasi & 47,2 \\
\hline 10 & d & Pengetahuan & $\begin{array}{l}\text { Mengintegrasikan informasi dari berbagai sumber ter- } \\
\text { hadap sistem informasi arsip secara manual dan el- } \\
\text { ektronik. }\end{array}$ & 33,3 \\
\hline
\end{tabular}

Hasil temuan yang didapat dalam penelitian ini adalah belum semua kompetensi matakuliah pendukung TAP ASIP4500 sesuai dengan kompetensi lulusan Program Diploma IV Pengelolaan Arsip dan Rekaman Informasi. Ada beberapa kompetensi keterampilan maupun pengetahuan lulusan yang belum terakomodir dalam kompetensi matakuliah pendukung TAP ASIP4500, antara lain:

a. Keterampilan mahasiswa dalam berkomunikasi secara efektif pada semua lapisan masyarakat yang relevan dengan dunia kearsipan.

b. Keterampilan mahasiswa dalam melakukan kegiatan preservasi arsip/dokumen secara benar.

c. Keterampilan mahasiswa dalam melakukan kajian atau penelitian dalam bidang kearsipan.

d. Keterampilan mahasiswa dalam melakukan publikasi dan pameran arsip.

e. Pengetahuan mahasiswa dalam menjelaskan perkembangan organisasi baik pemerintah maupun swasta.

f. Pengetahuan mahasiswa dalam menjelaskan perkembangan manajemen informasi dan dokumentasi.

g. Pengetahuan mahasiswa dalam menguasai pengetahuan teknik berkomunikasi secara efektif.

h. Pengetahuan mahasiswa untuk mengetahui struktur pengelolaan administrasi pemerintahan. 
Terbukti bahwa 29,6\% kompetensi lulusan belum sesuai dengan kompetensi matakuliah pendukung TAP ASIP4500. Walaupun matakuliah pendukung belum mengakomodir kompetensi pengetahuan dan keterampilan tersebut namun kedelapan kompetensi tersebut telah terakomodir dalam matakuliah lain. Contohnya kompetensi keterampilan dan pengetahuan komunikasi efektif ada dalam matakuliah Public Speaking, matakuliah reprografi merupakan bagian kompetensi preservasi dokumen. Selanjutnya segala hal yang berkaitan dengan kompetensi pengelolaan administrasi pemerintahan maupun perkembangan organisasi dipelajari dalam matakuliah Organisasi Tata Laksana Lembaga Kearsipan, Perilaku Organisasi, Pengembangan Organisasi, Administrasi Pemerintahan Daerah. Keterampilan publikasi dan pameran arsip dapat dipelajari didalam matakuliah Publikasi dan Pameran Arsip. Seluruh kompetensi lulusan sudah dipelajari mahasiswa selama proses perkuliahan.

\section{KESIMPULAN}

TAP ASIP4500 bertujuan untuk mengukur kemampuan mahasiswa Program Diploma IV Pengelolaan Arsip dan Rekaman Informasi secara komprehensif. Matakuliah pendukung TAP ASIP4500 antara lain ASIP4402 Penilaian dan Penyusutan Arsip, ASIP4432 Otomasi Dalam Kearsipan, ASIP4434 Perancangan Jadwal Retensi Arsip dan ASIP4436 Perancangan Skema Klasifikasi dan Tesaurus. Keempat matakuliah pendukung tersebut memiliki karakter kompetensi keterampilan dan pengetahuan yang berbeda - beda. Keempat matakuliah dipilih pihak prodi karena dianggap sebagai inti (core) ilmu kearsipan yang harus dipahami mahasiswa. Ditemukan ketidaksesuaian antara kompetensi mata kuliah pendukung TAP ASIP4500 dengan kompetensi lulusan Program Diploma IV Pengelolaan Arsip dan Rekaman Informasi UT. Temuan ini tergambar pada hasil prosentase hasil analisis. Matakuliah pendukung TAP ASIP4500 tidak sepenuhnya dapat merepresentasikan kompetensi mahasiswa, sebagaimana yang dideskripsikan dalam profil lulusan dan capaian pembelajaran matakuliah pendukung. Program Diploma IV Pengelolaan Arsip dan Rekaman Informasi merupakan bagian dari Universitas Terbuka yang menerapkan konsep pembelajaran jarak jauh. Kateristik utama pembelajaran jarak jauh adalah heterogenitas mahasiswa dan tersebar diseluruh penjuru nusantara, hal ini menjadi salah satu faktor kelemahan dalam melaksanakan pembimbingan tugas akhir. Pelaksanaan TAP ASIP4500 menjadi solusi evaluasi kompetensi profil lulusan, namun perlu dikaji kembali agar pemilihan mata kuliah pendukung TAP dapat merepresentasikan kompetensi profil lulusan program studi.

\section{DAFTAR PUSTAKA}

AAI. (2009). Keputusan Pengurus Nasional Asosiasi Arsiparis Indonesia Nomor 62/ AAI/2009 tentang kode etik profesi.

ANRI. (2017). Peraturan Kepala ANRI No 89 Tahun 8673 tentang Perubahan Perka ANRI No 5 Tahun 2016 Standar Kualitas Hasil Kerja Pejabat Fungsional Arsiparis. , Pub. L. No. Nomor 23 Tahun 2017.

Bukhori, F. (2019). Pengaruh Kompetensi Terhadap Kinerja Arsiparis di Arsip Nasional Republik Indonesia (ANRI). Jurnal Khazanah: Jurnal Pengembangan Kearsipan, 2019 Vol 12(1).

Faqih, A. (2014). Revitalisasi Mata Kuliah TAP Program S7 PGSD Untuk Mendukung Penyiapan Kompetensi Profesional Calon Lulusan. Tangerang Selatan: Universitas Terbuka. Diunduh melalui http://repository.ut.ac.id/5908/ 
Hutapea, P. (2008). Kompetensi Plus: Teori, Desain, Kasus Dan Penerapan Untuk HR Serta Organisasi Yang Dinamis. Diunduh melalui https://books.google.co.id/books? id=BahfG7VnoiYC\&pg=PA5\&dq=kompetensi+adalah\&hl=id\&sa=X\&ved=0ahUKE wi8hcvYqfjmAhXSR30KHa5nBzMQ6AEIKTAA\#v=onepage\&q=kompetensi adalah\&f=false

Indrawati, E. (2007). Penjaminan Kualitas Lulusan Melalui Penyelenggaraan Tugas Akhir Program. Jurnal Pendidikan Terbuka Dan Jarak Jauh, Vol. ${ }^{2}$ No., 1-14.

Kemendikbud. (1994). Keputusan Menteri Pendidikan dan Kebudayaan Republik Indonesia Nomor 056/U/1994. , Pub. L. No. 056/V/1994, 225 (1994).

Mantra I. (2008). Filsafat Penelitian dan Metode Penelitian Sosial. Yogyakarta: Pustaka Pelajar.

Menteri Pendidikan Nasional. 2000. Pedoman Penyusunan Kurikulum Pendidikan Tinggi Dan Penilaian Hasil Belajar Mahasiswa. Pub. L. No. NOMOR 676/U/6444.

Peraturan Pemerintah Republik Indonesia Nomor 8 Tahun 2012 tentang Kerangka Kualifikasi Nasional Indonesia. Pub. L. No. Nomor 8 Tahun 2012.

Peraturan Pemerintah Republik Indonesia Nomor 28 Tahun 2012 tentang Pelaksanaan Undang Undang Nomor 43 Tahun 2009 tentang Kearsipan.

Permenristekdikti. (2015). Peraturan Menteri Riset, Teknologi dan Pendidikan Tinggi RI Tentang Standar Nasional Pendidikan Tinggi. Pub. L. No. Nomor 88 Tahun 6459.

Sudiyanto. (2013). Beberapa Regulasi yang Menguatkan Eksistensi Arsiparis. Jurnal Ilmu Informasi, Perpustakaan dan Kearsipan, Vol. 12. Diunduh melalui http:// jipk.ui.ac.id/index.php/jipk/article/view/5.

Sudiyanto. (2014). Re6leksi SDM Arsiparis Dalam Menyongsong 09 Tahun Kearsipan Indonesia. Media Dirgantara Volume 9 No 1 Maret 2014.

Sugiyono. (2013). Metodelogi Penelitian Kuantitatif, Kualitatif dan R\&D. Bandung: ALFABETA.

Universitas Terbuka. (2005). Panduan belajar TAP Program Studi S1-Penyuluhan dan Komunikasi Pertanian. Jakarta: Universitas Terbuka. 